\title{
Healthcare system design and parttime working doctors
}

\author{
J. J. W. Molema • S. Groothuis • I. J. Baars • \\ M. Kleinschiphorst • E. G. E. Leers • A. Hasman • \\ G. G. van Merode
}

Received: 9 April 2007 / Accepted: 15 July 2007 / Published online: 26 September 2007

(C) Springer Science + Business Media, LLC 2007

\begin{abstract}
More doctors would like to work parttime. Since research on fitting healthcare system design with the structure of parttime jobs is lacking, we studied how parttime work for medical doctors could be enabled from a system design perspective. A theoretical analysis was performed, illustrated by two case studies. We conclude that introducing parttime work can provide the opportunity for improving system design and, therewith, performance. From the case studies it seems that work redesign can enable parttime work, and at the same time improve system performance. Better managing variability in the system contributed to this. The case studies results also showed that systems characterized by different levels of variability fit with different work contracts.
\end{abstract}

Keywords Healthcare system design · Working parttime . Variability · Simulation

\section{Introduction}

More and more physicians would like to work parttime [1-4]. In addition, the number of female specialists is expected to

J. J. W. Molema $(\varangle) \cdot$ S. Groothuis $\cdot$ I. J. Baars

M. Kleinschiphorst • E. G. E. Leers · G. G. van Merode

Department of Health Organization, Policy and Economics,

Faculty of Health, Medicine and Life Sciences,

Care and Public Health Research Institute (CAPHRI),

Maastricht University,

P.O. Box 616, 6200 MD Maastricht, The Netherlands

e-mail: H.Molema@beoz.unimaas.nl

\section{A. Hasman}

Department of Medical Informatics, University Medical Centre,

University of Amsterdam,

P.O. Box 22660, 1100 DD Amsterdam, The Netherlands keep rising in the next years, which will further increase the demand for parttime jobs [1-7]. To accommodate these demands for flexibility in working hours, (more) opportunities for working parttime and/or sharing jobs should be created. Such opportunities can make the profession more alluring, which is important, considering the expected shortage of physicians $[3,8]$.

Currently, relatively few parttime jobs for physicians exist in healthcare. For example, in The Netherlands, only $6 \%$ of the surgeons in university hospitals work parttime, while $54 \%$ would like to [9]. The Netherlands Organization for Health Research and Development, affiliated to the Dutch government, funded a research program to explore opportunities for working parttime in healthcare: 'Parttime work among medical specialists.' The study discussed in this paper was part of this program and focused on parttime work from a logistical viewpoint.

Increasing research is being performed on the effects of physicians working parttime in healthcare [4-12]. Several of these studies reported no differences between parttime and fulltime physicians in terms of (quality) performance $[11,12]$. Also, a system with flexible, parttime employees at its disposal can design its process differently [13]. Having a flexible pool, for example, could enable a better reaction to fluctuations in demand per week, day or even per hour [14]. Such issues related to applicability and effects of parttime work may, according to Parkerton et al. [11] and Murray et al. [12], interact with the structure of the system in which the parttime work is performed. However, no studies on parttime work from the viewpoint of fitting the (logistical) design of a production system with the structure of jobs are known to the authors.

Therefore, we explored the nature of the relations between system design and parttime work. Our central research question was: "What is required for enabling 
working parttime in healthcare organizations?" Our study focused on enabling working parttime from a system's perspective; not a financial or human resource perspective.

Redesigning work to enable parttime work may change the organization of care processes and, consequently, can affect system design and performance. We will first elaborate on these relations. Subsequently, for illustration, two cases are introduced which represent two different hospital production systems. In both cases, computer simulation was applied to gain insight into enabling parttime work [15]. The simulation study is described and its results are discussed. Finally, we conclude on how an organization can enable work redesign challenges like parttime work. The aim of this paper is not only to provide insight on the subject interesting for managers faced with having to deal with a challenge like parttime work, but also for doctors thinking about working parttime.

\section{Healthcare system design}

A system is the means by which a process occurs, i.e. it provides the structure for a process to function in [16]. A production process is any activity or group of activities undertaken to transform input into output $[17,18]$. Flows, i.e. the movements of resources [18], exist both within and between processes.

Healthcare production systems contain various flows, such as patient, resource, information, and material. Through their production systems, healthcare organizations aim to offer value adding activities for patients and secure efficient, high quality patient care $[15,19-22]$. To do so, production system design should enable continuous patient flow and efficient performance [23]. However, in many hospitals discontinuity characterizes patient flows, in the form of series of queues from one activity to the next, [24]. Discontinuity can cause variability in the service process as well as system performance and can make a system difficult to manage $[24,25]$.

\subsection{Discontinuity}

System characteristics causing discontinuity in flow can be grouped into three categories: (1) uncertainty, (2) inflexibility, and (3) complexity of coordination [24]. Uncertainty relates to the extent of information being either unavailable or available but unused. This information can concern demand, supply or the service process itself. Inflexibility determines the degree of adaptability of the production system to changes in demand. Adaptability can be restricted due to technical, economic, or staff inflexibility. Coordination complexity concerns the number of transactions and transfers. Coordination is complex in processes and subsystems that share resources. Sharing leads to transfers of information, capacity, personnel, materials, etc. Since most processes and systems in healthcare share resources, flows are interdependent.

Variability, either inherent or preventive, affects the efficiency attainable in a system, system performance, and quality of patient care [18, 24-27]. In healthcare a lot of variability is present, e.g., random or non-uniform arrival rates, service times, outcomes, but also a variety of treatment options for one diagnosis [25-27]. Managing variability to predict flow and to improve performance is one of the main objectives in operations management [24, 26]. In Lean Thinking variability is managed, among other things, through work design. An example of such work design is standardizing processes' and systems' designs by using standardized documentation according to which the workers must perform [28]. This can reduce waste as well as uncertainty, staff inflexibility, and complexity of coordination $[14,18,24,27-31]$.

\subsection{Managing discontinuity through parttime work}

Work contracts specify the duties to be fulfilled by a worker. The organization that employs the worker has jobs designed to fulfill these duties. In healthcare, job designs determine which tasks a physician should fulfill, when and how to fulfill them and how much time is available for this. Thus, through the design of jobs, work contracts may directly affect system design and performance. Moreover, as job design may influence the continuity of flow, work contracts are an important element of system design. This means that if a certain system is characterized by some level of variability and discontinuity, also the work contract should be evaluated $[12,32,33]$. Let us carry a comparison to working parttime.

Introducing parttime work in a system may require changing the design of work and tasks. Creating parttime work in a system could imply a re-allocation of personnel to activities as well as changed workstation, task, and operator related restrictions [29]. In fact, creating parttime work in a system is a type work redesign. Hackman [34] defines work redesign as "any activities that involve the alteration of specific jobs with the intent of increasing both the quality of the employees' work experience and their onthe-job productivity."

Redesigning work via parttime jobs may be used as a management instrument. Having a pool of flexible employees can benefit an organization and restrict discontinuity in flows $[13,24]$. It could help standardize processes and reduce variability. For example, to flexibly respond to changes in demand, a system requires flexible staff in terms of availability and capabilities. Often, parttime workers can provide this flexibility. There may, however, be constraints 
to introducing parttime work [12]. For example, a system in which many resources are shared may not benefit from introducing parttime workers, since this may further increase the number of transactions. Also, if a parttime worker demands to work only morning shifts, the system in which he works must facilitate a low variation in shift durations. If this is not the case, the demanded contract should not be implemented or the system redesigned.

Different contracts for parttime work exist [13]. Contract types differ on the basis of several variables. A first distinction in contract types stems from deciding on the number of hours to work per day and week and on how to assign these. A parttime contract with fixed work hours and days can be called a day-based contract [35]. Minimum/ maximum contracts are more flexible parttime contracts. They specify the minimum work hours per week which can be extended to a specified maximum, if necessary [35]. The second distinction in contract types is how the parttime physician organizes his work. He can either share or split a fulltime job [1, 13]. Job sharing implies two physicians equally sharing all tasks of one job. The whole job is the couple's responsibility. This requires finding a suitable partner; something, that may be difficult and therefore can impede parttime work [2]. Job splitting implies splitting up a whole job or single tasks into smaller parts. Each physician is responsible for his own part. This solves the problem of finding a partner. At the same time, splitting a job can make that job less attractive because it can affect skill variety if the new job no longer comprises the full range of responsibilities and skills.

The various contracts were studied further in a simulation study carried out for two cases, each characterized by a different system design.

\section{Case studies}

We used a multiple case study to explore how parttime contracts and system design interact. Also, we studied how this interaction affects discontinuity in the system, measured in in-process variability and performance. Two cases were selected and described using process mapping [36]. Next, we developed simulation models in MedModel ${ }^{\circledR}$
[37], a discrete event simulation program. To this end, we used the flow charts complemented with historic patient data over 1 year. After validating and simulating the models of current situations in both cases, scenarios in which parttime contracts were enabled were set up and evaluated.

\subsection{Case descriptions}

Case 1 concerned the work process of surgeons specialized in care for elective patients with intestinal problems in the surgery department of a Dutch university hospital. Of their total work time, the surgeons spent $40 \%$ of their time on this process. Figure 1 displays patient flow in the process.

Overall, the surgeons' work process resembled a jobshop design and the overall system design could be characterized as an "Archipelago" [24]. Additionally, the treatment process for the patients was multidisciplinary. This made flow coordination complex. So did the fact that capacities in the process were shared with others. Also affecting the complexity of coordination was that the surgeon who operated on the patient had to visit the patient. These visits took place at the ward preoperatively, 1 day before surgery, and postoperatively, the evening after surgery as well as several days later at the outpatient clinic. Besides, task times varied greatly as did times between activities. Overall patient throughput times were days to weeks. All this resulted in many transfer points and jumbled patient flows.

Case 2 concerned work processes of the three gastroenterologists working in the endoscopy department in a Dutch general hospital. The study focused on patients receiving gastroscopy, colonscopy or sigmoidoscopy. The gastroenterologists spent $50-60 \%$ of their total working time at the department. Figure 2 displays the patient flow at this department.

Work design in the monodisciplinary endoscopic process resembled a product-line and overall system design could be characterized as a "Procedure based factory" [24]. Coordination was not complex because no capacity was shared and patients met the gastroenterologist only in the endoscopy room. Also, since most patients were outpatients and thus not transferred to and from wards, transfer points were few. The focus in the process was on the medical

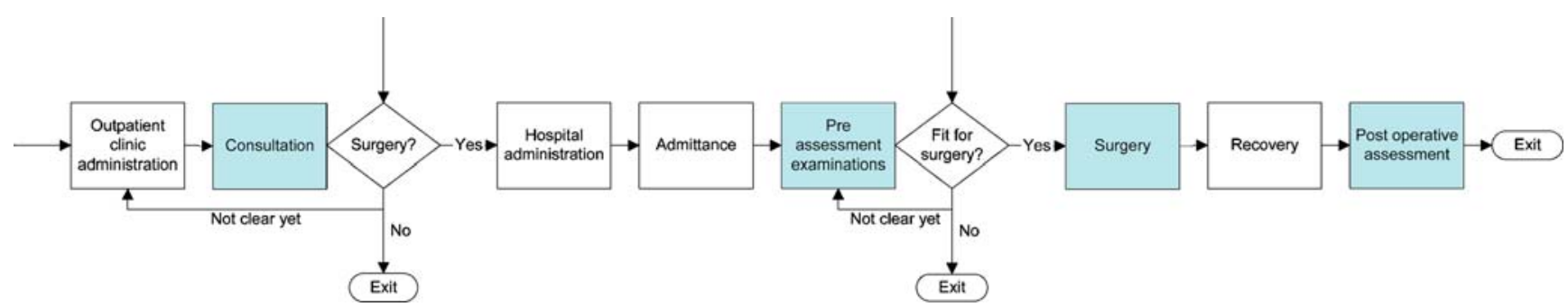

Fig. 1 Flowchart of patient flow at surgery department (all arrows represent patient flows between activities; all shaded squares represent activities in which surgeons perform tasks) 


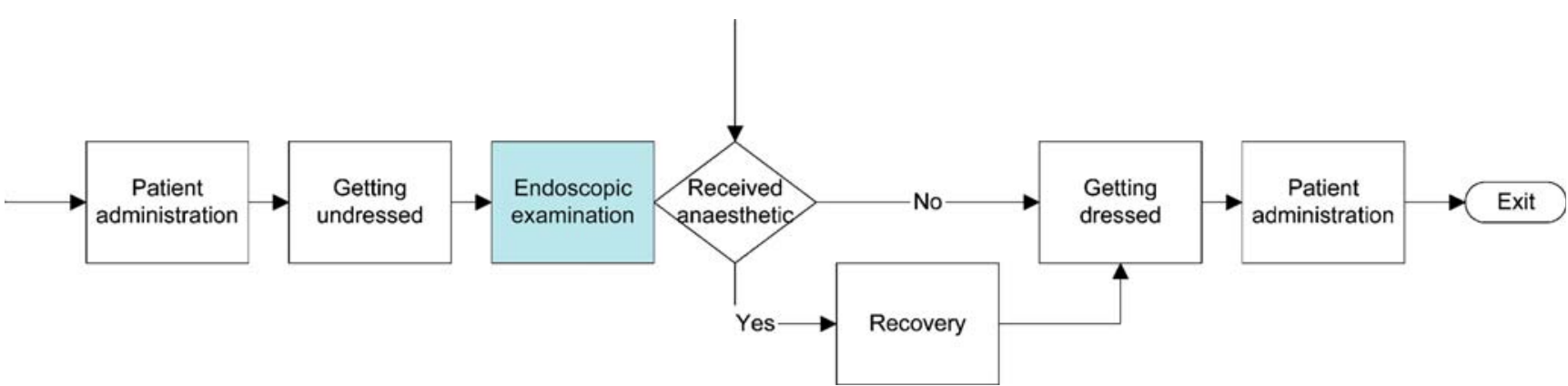

Fig. 2 Flowchart of patient flow at endoscopy department (all arrows represent patient flows between activities; all shaded squares represent activities in which the gastroenterologist performs tasks)

intervention (the endoscopy) and not on continuous patient flow. Task times were uncertain and patient flow was discontinuous at times, because patients waited at some points in the process. Patient throughput time was somewhat over $30 \mathrm{~min}$.

\subsection{Comparing the cases}

Overall, both work and system designs were less standard in the surgery department (case 1) than in the endoscopy department (case 2). Case 1 was characterized by more uncertainty and required more complex coordination. The differences between the cases may be (partly) explained by the patient mix. In case 1 , patients were more medically complex and needed a multidisciplinary process delivered at several locations. Further, during a shift the surgeons in case 1 were not solely allocated to the selected patient group, whereas the gastroenterologists in case 2 were. Patient throughput times in case 1 far exceeded throughput times in case 2. These differences were expected to influence the possibilities for parttime work per case.

Table 1 displays the results of simulating the current situations. It shows that both cases contained variability (expressed in the standard deviations). However, case 1 more than case 2. Taking into account this variability in both cases, we set up scenarios to explore the possibilities for enabling parttime contracts and restricting discontinuity in flow as much as possible.

\subsection{Simulation scenarios}

As described in part 2.1, discontinuity in flow can be caused by complexity of coordination, staff inflexibility, and uncertainty. These three factors were used to define variables for setting up the simulation scenarios. Additionally, two strategies for enabling parttime work in a system were applied for setting up the scenarios. The first strategy implied selecting a contract to directly enable parttime work. By doing so, we aimed to create a flexible system design, reduce variability, and optimize flow. The second strategy meant indirectly enabling parttime work. Follow- ing this strategy, we reduced variability first to manipulate system design and to make system design better fit the parttime work contract.

In the surgery department, we applied both strategies to the three variability related factors. Firstly, parttime work was directly enabled through decoupling the complex doctor-patient relationship. For the scenario, the surgeon who performed surgery on a patient no longer had to visit that patient preoperatively and postoperatively. This could now also be a different surgeon, which enabled, for example, working according to a day-based contract. Secondly, parttime work was directly enabled for the surgeons by decreasing staff inflexibility and splitting their tasks at the outpatient clinic and transferring some of them to a nurse specialist. Thirdly, parttime work was indirectly enabled. Uncertainty in service times was reduced to study the effect of this decrease in variability on process performance, especially duration of the workday. No longer were patients scheduled using general average operation durations, characterized by large standard deviations. Instead, for the scenario, the patient population was split up into subgroups, each characterized by a more homogeneous average operation duration and smaller standard deviation [38].

Table 1 Current situation in the surgery department and endoscopy department

\begin{tabular}{lrlr}
\hline Surgery department & \multicolumn{3}{c}{ Endoscopy department } \\
\hline Throughput time (in days) & & Throughput time (in min) \\
Avg. & 36 & Avg. & 35 \\
Median & 34 & Median & 34 \\
Std. Dev. & 7 & Std. Dev. & 3 \\
Shift exceeded (in min) & & Morning shift (in min) \\
Avg. & 93 & Avg. & 203 \\
Median & 87 & Median & 201 \\
Std. Dev. & 146 & Std. Dev. & 9 \\
Room utilization (in \%) & & Workday (in min) & \\
Avg. & 63 & Avg. & 443 \\
Median & 62 & Median & 441 \\
Std. Dev. & 9 & Std. Dev.
\end{tabular}


Since current performance in the endoscopy department was such, that neither a complex doctor-patient relationship nor opportunities for task transfer existed, the scenarios focused on indirectly enabling parttime work through reducing uncertainty in service times. For the scenarios, the uncertainty in service times was manipulated (more and less uncertainty) and the effects on performance were measured.

\subsection{Results scenarios}

In case 1, decoupling the surgeon-patient relationship at the operating theatre decreased throughput time and increased production (Table 2). However, extra information transfers among the surgeons may be needed which could add complexity. In the second scenario, adding a nurse specialist to take over surgeon tasks at the outpatient clinic did not significantly influence throughput time. This could be expected, since no differences were assumed between the surgeons and the nurses regarding consultation time [39].

Table 3 shows that reducing uncertainty in service times in the surgery department improved performance. The predictability of shift duration and utilization of operating capacity improved. However, planned shift time was still exceeded, although, much less frequent.

Simulation results of the scenarios in the endoscopy department made clear that decreasing uncertainty in service times improved process predictability and performance. Not only was the process predictability increased by this decrease in supply variability. Also, patients flowed more continuously. Vice versa, the simulations showed that more variability resulted in increased patient throughput time, caused by increased queuing. Besides, uncertainty regarding patient throughput time increased and the predictability of shift endpoints decreased (Table 4).

\section{Discussion}

The results of the case study underpin that different systems, i.e. different system designs, lend themselves for

Table 2 Reducing staff inflexibility and complexity at surgery department (250 replications)

\begin{tabular}{llll}
\hline $\begin{array}{l}\text { Scenario } \\
\text { Performance } \\
\text { indicator }\end{array}$ & $\begin{array}{l}\text { Current } \\
\text { situation }\end{array}$ & $\begin{array}{l}\text { Decoupling } \\
\text { doctor-patient } \\
\text { relationship }\end{array}$ & $\begin{array}{l}\text { Transferring } \\
\text { tasks }\end{array}$ \\
\hline Throughput time (in days) & & \\
Avg & 36 & $33^{*}$ & 36 \\
Median & 34 & 31 & 34 \\
Std. Dev. & 7 & 7 & 7 \\
\hline
\end{tabular}

*Significant difference $p<0.05$
Table 3 Reducing uncertainty in patient scheduling at surgery department (500 replications)

\begin{tabular}{lcl}
\hline $\begin{array}{l}\text { Scenario } \\
\text { Performance indicator }\end{array}$ & $\begin{array}{l}\text { Current } \\
\text { situation }\end{array}$ & $\begin{array}{l}\text { Creating } \\
\text { subgroups }\end{array}$ \\
\hline Shift exceeded (in min) & & $21^{*}$ \\
Avg & 93 & 11 \\
Median & 87 & 97 \\
Std. Dev. & 146 & $62 *$ \\
Room utilization (in \%) & 63 & 62 \\
Avg & 62 & 6 \\
Median & 9 & \\
Std. Dev. & & \\
\hline
\end{tabular}

*Significant difference $p<0.05$

different parttime contracts. In case 1, the high level of uncertainty about shift endpoints will conflict with fixed daybased contracts. Case 1 demands more flexible minimummaximum contracts. Also, job splitting is possible in case 1 by splitting tasks at the outpatient clinic from surgery tasks. Job sharing can be applied in case 1 if the two surgeons that make up the couple operate as one and perform one full job together. However, if both surgeons work on more than a $50 \%$ basis, more than one job needs to be coordinated which makes the system more complex. And since process coordination is already complex in case 1 , job sharing seems less suitable.

The production system in case 2 contains less uncertainty, so a day-based contract may be applicable, despite the somewhat uncertain task times. Job splitting is not possible in case 2 , since the gastroenterologists only perform one task in the system. Job sharing is possible and will not increase complexity, since the process already takes place in two clearly defined shifts (morning, afternoon) that the couple can share. This also makes job sharing attractive if the two physicians making up a couple want to work on more than a $50 \%$ basis.

The simulation scenarios mainly focused on variability management to optimize patient flow. The results made clear that directly enabling parttime work can reduce inprocess variability. This way, parttime work can favor patient throughput times as well as the probability that scheduled work hours and shift endpoints can be upheld. Reducing uncertainty first leads not only directly to improved performance, but also makes it possible to better implement parttime jobs.

Of course, all production systems in healthcare should manage variability and standardize patient processes to the extent possible [24]. However, process standardization may imply job inflexibility and reduced quality of jobs and work perception [34]. Therefore, an organization should continuously make a tradeoff between process standardization and employee flexibility. Adler, Goldoflas, and Levine [32] 
Table 4 Reducing and increasing uncertainty in demand and supply in the endoscopy department (250 replications)

*Significant difference $p<0.05$

\begin{tabular}{|c|c|c|c|c|c|}
\hline \multirow{2}{*}{$\begin{array}{l}\text { Experiment } \\
\text { Performance indicator }\end{array}$} & \multirow[t]{2}{*}{ Current situation } & \multicolumn{2}{|c|}{$\begin{array}{l}\text { Decreasing uncertainty } \\
\text { in task times }\end{array}$} & \multicolumn{2}{|c|}{$\begin{array}{l}\text { Increasing uncertainty } \\
\text { in task times }\end{array}$} \\
\hline & & $-20 \%$ & $-30 \%$ & $+20 \%$ & $+30 \%$ \\
\hline \multicolumn{6}{|c|}{ Throughput time (in min) } \\
\hline Avg & 35 & $34 *$ & $34 *$ & $36^{*}$ & $37 *$ \\
\hline Median & 34 & 33 & 33 & 35 & 36 \\
\hline Std. Dev. & 3 & 2 & 2 & 4 & 5 \\
\hline \multicolumn{6}{|l|}{ Morning shift (in min) } \\
\hline Avg & 203 & 202 & 202 & 203 & 204 \\
\hline Median & 201 & 202 & 202 & 200 & 203 \\
\hline Std. Dev. & 9 & 6 & 5 & 11 & 12 \\
\hline \multicolumn{6}{|l|}{ Workday (in min) } \\
\hline Avg & 443 & $441 *$ & $440 *$ & $445^{*}$ & $447 *$ \\
\hline Median & 441 & 441 & 442 & 442 & 445 \\
\hline Std. Dev. & 9.3 & 5 & 5 & 15 & 18 \\
\hline
\end{tabular}

mention two job-related structures that can increase the attractiveness of standardized processes while upholding an efficient system design: (1) job enrichment (enables workers to become more innovative and flexible in the course of routine tasks) and (2) job switching (differentiates roles for dealing with two kinds of tasks). These structures could be interwoven with parttime work contracts.

In our study we focused on the relation between parttime work and system design. It should be clear that for deciding on implementing parttime work more factors should be taken into account. For example, in our study we did not pursue the matter of costs associated with parttime work. Neither did we address the issue of working parttime and quality of care, in terms of ensuring continuity of care [2]. This continuity may be harmed if more physicians perform tasks within the same system. Also, no attention was paid to the human resource strategy necessary to attract enough staff to truly enable parttime work. A government, like the Dutch, should not only proclaim to implement parttime jobs in healthcare and to limit work hours per staff member. Also, it should facilitate both creating parttime educations programs and securing enough places in the medical education programs as well as the specialization training programs [1, 5]. Hospitals themselves should become environments that value parttime workers and provide the opportunities for employing them $[5,8]$.

\section{Conclusions}

The study discussed in this paper adds to the current knowledge about working parttime in healthcare. It shows that, from a logistical viewpoint, creating opportunities for working parttime seems very much possible. Enabling parttime work successfully requires insight into the logistics of a production system as well a comprehensive understanding of the system design. The study underlines that a parttime contract is an intermediate variable between work design, system efficiency, variability, and quality of work. Based on the results of the simulation studies, we can conclude that offering parttime jobs can introduce flexibility in system design and can improve the care delivery process, patient flow, and performance. Thus, parttime work can be attractive for both physicians and patients.

Regarding the method applied, we can say that the case studies presented examples from practice and clarified the relations among system design, variability, work design, and performance. The case studies results also showed that systems of different character fit with different work contracts. Especially, variability is a factor to be reckoned with in choosing work contracts and designing jobs and systems. Both managers and doctors should take note of this when they choose to select parttime work contracts.

The comparability of the two cases discussed in this paper may be limited, since both had a clinically very different setting. Also, generalizability is limited since only two cases were studied. Further research could focus on comparing departments with the same clinical function, the same patient mix, but with a different structure. Additionally, it would be interesting to apply the proposed approach to an entire hospital.

Acknowledgements We would like to thank The Netherlands Organization for Health Research and Development, ZonMw for funding this research project. Also, we greatly acknowledge the department of Surgery of the university hospital Maastricht, The Netherlands, and the Endoscopy department and the department of Internal Medicine of the Catharina hospital Eindhoven, The Netherlands, for their cooperation in this research. 


\section{References}

1. Mather HM (2001) Specialist registrars' plans for working part time as consultants in medical specialties: questionnaire study. $\mathrm{Br}$ Med J 7302:1578-1579

2. Ramsay R (2000) Working part time as a consultant. Br Med J Career Focus 7272:2-7273

3. Gibson H (1997) Are part time doctors better doctors? Br Med J 7113(suppl):2-3

4. de Jong J, Heiligers P, Groenewegen P, Hingstman L (2006) Parttime and full-time medical specialists, are there differences in allocation of time? BMC Health Serv Res 1:26

5. Evans J, Goldacre MJ, Lambert TW (2000) Views of UK medical graduates about flexible and part-time working in medicine: a qualitative study. Med Educ 5:355-362

6. Kermode-Scott B (2004) Changes in Canada's medical workforce could affect access to care. Br Med J 329(7474):1064

7. Cull WL, Mulvey HJ, O'Connor KG, Sowell DR, Berkowitz CD, Britton CV (2002) Pediatricians working part-time: past, present, and future. Pediatrics 6:1015-1020

8. McMurray JE, Heiligers PJM, Shugerman RP, Douglas JA, Gangnon RE, Voss C, Costa ST, Linzer M (2005) Part-time medical practice: where is it headed? Am J Med 1:87-92

9. Van der Vange N, Vriend M, Slootman KCP, Heiligers P (2003) Working flexibly (in Dutch). Med Contact 15

10. Lugtenberg M, Heiligers P, de Jong J, Hingstman L (2006) Internal medicine specialists' attitudes towards working part-time: a comparison between 1996 and 2004. BMC Health Serv Res 1:126

11. Parkerton PH, Wagner EH, Smith DG, Straley HL (2003) Effect of Part-time Practice on Patient Outcomes. J Gen Intern Med 9:717-724

12. Murray A, Safran DG, Rogers WH, Inui T, Chang H, Montgomery JE (2000) Part-time physicians: physician workload and patientbased assessments of primary care performance. Arch Fam Med 4:327-332

13. Hamilton S, Wilson R, Butcher A (2000) Hospital trusts' views on flexible career grades. BMJ Br Med J Int 7226(Suppl):2-3

14. Liker JK (2004) The toyota way. McGraw-Hill, New York

15. Young T, Brailsford S, Connell C, Davies R, Harper P, Klein JH (2004) Using industrial processes to improve patient care. Br Med J 7432:162-164

16. Anthony RN (1965) Planning and control systems - a framework for analysis. Division of Research, Graduate School of Business Administration, Harvard University, Boston, MA

17. Chase RB, Aquilano NJ (1995) Production and operations management: manufacturing services. Irwin, Homewood, IL

18. Krajewski LJ, Ritzman LP (2002) Operations management. Prentice Hall, Upper Saddle River, New Jersey

19. Porter ME, Teisberg EO (2006) Redefining health care: creating value-based competition on results. Harvard Business School Press, Boston, MA
20. Herzlinger RE (2004) Consumer driven healthcare: implications for providers, payers, and policymakers. Jossey-Bass, San Francisco

21. Van Merode GG (2004) A prelude to the 2004 Antwerp Quality Conference: targets and target values - integrating quality management and costing. Accredit Qual Assur 168-171

22. Young $\mathrm{T}$ (2005) An agenda for healthcare and information simulation. Health Care Manage Sci 189-196

23. Donaldson L (2000) Design structure to fit strategy. In: Locke EA (ed) The Blackwell handbook of principles of organizational behavior. Blackwell, Oxford

24. Van Merode F, Molema H, Goldschmidt H (2004) GUM and six sigma approaches positioned as deterministic tools in quality target engineering. Accredit Qual Assur 10:32-36

25. Hopp WJ, Spearman ML (2001) Factory physics: foundations of manufacturing management. McGraw-Hill, New York

26. Noon CE, Hankins CT, Cote MJ (2003) Understanding the impact of variation in the delivery of healthcare services. J Healthc Manag 2:82

27. McLaughlin CP (1996) Why variation reduction is not everything: a new paradigm for service operations. Int J Serv Ind Manage 9:17-30

28. De Treville S, Antonakis J (2006) Could lean production job design be intrinsically motivating? Contextual, configurational, and levels-of-analysis issues. J Oper Manag 2:99-123

29. Becker C, Scholl A (2006) A survey on problems and methods in generalized assembly line balancing. Eur J Oper Res 3:694-715

30. Womack JP, Jones DT (2003) Lean thinking — banish waste and create wealth in your corporation. Free, New York (revised and updated)

31. Ballé M, Régnier A (2007) Lean as a learning system in a hospital ward. Leadersh Health Serv 1:33-41

32. Adler PS, Goldoflas B, Levine DI (1999) Flexibility versus efficiency? A case study of model changeovers in the Toyota Production System. Organization Science 1:43-68

33. Tummers GER, Landeweerd JA, Van Merode GG (2002) Work organisation, work characteristics and the psychological effects on nurses in The Netherlands. Int J Stress Manag 3:183-206

34. Hackman JR (1977) Work design. In: Hackman JR, Suttle JL (eds) Improving life at work: behavioral science approaches to organizational change. Goodyear, Santa Monica, CA, pp 96-162

35. Heiligers P (2001) Working part-time; only few people choose the best opportunity. Med Contact 47:1739-1741 (in Dutch)

36. Okrent MD, Vokurka RJ (2004) Process mapping in successful ERP implementations. Ind Manage Data Syst 8:637-643

37. http://www.promodel.com/products/medmodel/, MedModel (Accessed on: 01-07-2007)

38. Van Merode GG, Groothuis S, Hasman A (2004) Enterprise resource planning for hospitals. International Journal of Medical Informatics 6:493-501

39. Vrijhoef HJ, Diederiks JP, Spreeuwenberg C, Wolffenbuttel BH, van Wilderen LJ (2002) The nurse specialist as main care-provider for patients with type 2 diabetes in a primary care setting: effects on patient outcomes. Int J Nurs Stud 4:441-451 